\title{
Overview of Buddhism and the Concept of Suffering
}

\author{
Michele Riley Kramer* \\ College of Nursing and Health Sciences, Lewis University, USA
}

*Corresponding author: Michele Kramer, Associate Professor in College of Nursing and Health Sciences (CONHS), Lewis University, Romeoville, USA.

Received Date: December 19, 2019

Published Date: January 23, 2020

\begin{abstract}
Buddhism is a way of thinking and living that is used as a philosophy, a psychology, a religion, and a spiritual tradition. It began with the teachings from Lord Siddhartha about his experiences and journey toward enlightenment. His teachings were written down approximately three hundred years after his earthly existence. His teachings have since been followed literally or interpreted more broadly. Buddhism has influenced, and in return has been influenced by, other cultures. These cultures took what they felt to be important and integrated them with their own wisdom traditions. Hence, Buddhism and its expression vary throughout the countries that embraced it. The purpose of this paper is to broadly outline Buddhist teachings and their variations. The rest of the paper will focus on the Buddhist concept of suffering, which is the basis and main premise of Buddha's teachings.
\end{abstract}

\section{Overview of Buddhism}

Buddhism began with the revelations received by a man named Siddhartha, or Gautama His revelations were not new but were realizations of ancient ageless wisdom brought through to him in answer to his question and quest to find the cause of, and a way to relieve it, suffering in the world [1,2]. Buddha is said to have lived about 650 B.C.E. or 450 B.C.E., but the former date is the most used. He lived in Northern India in a time where asceticism was the popular form of spiritual pursuit. He is said to have received enlightenment after sitting under a Bodhi tree for a great length of time. Afterward, he passed on what he learned to a group of loyal fellow ascetics who then began teaching as well. Monasteries were built so that those individuals in pursuit of enlightenment would have a place to pursue their path.

Buddhism branched into different sects within India before spreading outside to other countries. The splits and divisions resulted from conflicts over interpretation and practice. Fewer arhats (those who had achieved enlightenment), doctrinal strife and dissension, and "the demand of the laity for more equal rights with monks" contributed to the splits [1]. Although the origins are obscure, the Mahayana movement arose between 100 B.C.E. and 100 C.E. in opposition to those who followed the true and original Buddhist teachings (of which the Theravadin sect is the major school remaining). They were less exclusive than the Theravadins, opening their teachings to lay people. Those who believed in following the essence of the teachings and interpreting them (eventually designated as Mahayana) split from the main body that maintained and followed the teachings of Buddha in its original form (of which the Theravadin sect is the largest remaining) [1]. Asserts that development of Mahayana Buddhism, the main severance from the original practice and teachings, was necessary in order to appeal to the other cultures in which Buddhism spread its influence. Followers of what eventually became the Mahayana sect believed the doctrines and teachings of Buddha were stale and that the creation of new literature would keep Buddhism alive. Five new ideas evolved that distinguished Mahayana from the original (Theravadin) beliefs [1].

A. "shift from the Arhat-ideal to the Bodhisattva-ideal".

B. "a new way of salvation is worked out, in which compassion ranks equal with wisdom, and which is marked by the gradual advance through six 'perfections' (paramita)".

C. a new set of deities evolved, "or rather persons more than divine".

D. ''Skill in means' (upayakausalya), an entirely new virtue, becomes essential to the saint, and is placed even above wisdom, the highest virtue so far".

E. "A coherent ontological doctrine is worked out, dealing with such items as 'Emptiness', 'Suchness', etc." 
Theravadin Buddhists see the culmination of wisdom and achievement of nirvana in human form as the arhat (or arahat). Mahayana Buddhists argue that arhats achieve this state for their own personal satisfaction while the bodhisattvas, the highest human pinnacle of the same achievement, do so in order to be able to help others. It is a significant difference between the sects [3]. According to Robinson R \& Johnson W [4], "The Mahayana innovation was to proclaim that the bodhisattva course is open to all, to lay out a path for aspiring bodhisattvas to follow, and to create a new pantheon and cult of superhuman bodhisattvas and cosmic Buddhas who respond to the pleas of devotees". It is important to mention another sect, Buddhist Tantra, in relation to the Buddhism characteristic of Tibet and Northern India. According to Robinson R \& Johnson W [4], "Buddhist Tantra is a mysticism mixed with magic", an amalgamation of both Buddhist and non-Buddhist concepts that do not rest with any one Indian religion. It came about around the sixth century C.E., in the areas in Northern India, about the same time that Buddhism was introduced into Tibet. Tibetan Buddhism is unique in its mixture of Mahayana and Tantric Buddhist influences, as well as aspects of its indigenous Bon religion.

About written literature, the earliest written Buddhist teachings were written approximately 80 B.C.E. According to Harvey P [3], there are six (non-Theravadin early canons preserved in Chinese and Tibetan translations, fragments of a Sanskrit Canon still existing in Nepal, and odd texts in various languages of India and Central Asia found in Tibet, Central Asia, and Japan". The Mahayana's generated a body of literature, called Sutras that were written in Sanskrit rather than the original Pali language. Harvey also notes "The main sources for our understanding of Mahayana teachings are the very extensive Chinese and Tibetan Buddhist Canons. While most of the Pali Canon has been translated into English, only selected texts from these have been translated into Western languages, though much progress is being made" [3]. Although each country whose people adopted Buddhism integrated it with aspects of their own belief systems, and created new literature as well, the main structure and teachings of either Theravadin or Mahayana are their foundations. The countries that practice primarily Theravadin Buddhism are Ceylon, Laos, Thailand, Myanmar, and Cambodia. Those countries whose Buddhism is primarily Mahayana are China, Vietnam (influenced by Chinese Buddhism and Indian practices), Northern India, Nepal, Korea (Chinese Buddhist influence), Tibet, and Japan, in the form of the Chinese Chan but called Zen [1,4].

\section{Buddha's Teachings}

His Holiness the Dalai Lama states that there are "Three Jewels of Buddhism" that signify whether individuals are practicing Buddhists or not. He identifies practicing Buddhists as those who believe and accept "the Buddha; the Dharma, his teaching; and the Sangha or community of practitioners" [5]. What follows is an overview of the main teachings of Buddha. A plethora of texts have been written explaining various aspects of Buddha's teachings in detail. However, due to the limitations of this paper, my intent is to provide some idea of Buddha's teachings in order to concentrate in greater depth on Buddha's concept of dukkha (Pali) and my understanding of the concept. Dukkha is the seed, the central point, and the reason for Buddha's spiritual quest. It is the center point from which his discourses originate and the original premise of his teachings.

Simplistically, the main teachings (dharma in Sanskrit, dhamma in Pali) of Buddha consist first of the Four Noble Truths, which explain the main problem of human existence (suffering), its cause, and its remedy. The remedy is the Noble Eightfold Path called the Middle Way or the Middle Path. The Eightfold Path consists of eight "right" forms of living, thinking, and being. The rest of Buddha's teachings are more detailed explanations and commentaries of the concepts associated both with the Four Noble Truths and the Noble Eightfold Path. The Four Noble Truths define the reason, cause and cure for freeing human existence from dukkha, frequently translated as suffering. Dukkha is an internal creation of the individual and is not externally created. Therefore, only the individual is responsible for creating and alleviating suffering, or dukkha. Humans can free themselves from suffering by following the Noble Eightfold Path of Enlightenment. The goal is to reach enlightenment, or nirvana (Sanskrit; in Pali, nibbana), through escaping and freeing oneself from dukkha, and from recognizing that all life, all existence is impermanent, samsara (Sanskrit) an illusion [3-6].

Five qualities, factors, or aggregates are the basis for the self, the personality, of the individual. They are matter, sensations, perceptions, mental formations, and consciousness [7]. These five aggregates contribute to dukkha. Therefore, eliminating the personality, the self, will free the individual from dukkha. One realizes the "No-Self", which is a primary tenet of Buddhism, on the path to nirvana. The Noble Eightfold Path consists of eight "correct" behaviors that, if followed and developed, lead to enlightenment, or nirvana. They are grouped or correspond to the three Buddhist principles of wisdom, ethical conduct (love and compassion), and mental discipline. They are the right:

I. Understanding (wisdom)

II. Thought (wisdom)

III. Speech (ethical conduct)

IV. Action (ethical conduct)

V. Livelihood (ethical conduct)

VI. Effort (mental discipline)

VII. Mindfulness (mental discipline)

VIII. Concentration (mental discipline) [7].

The Eightfold Path is also called the Middle Way, or Middle Path, because it avoids the extreme of asceticism, which was the popular lifestyle in India for attaining higher spiritual development during Buddha's life. It also avoids the other extreme on the continuum, the opposite of asceticism, of sloth and debauchery. It is a path of moderation and respect for one's mind and body. Meditation is 
the vehicle used on to reach enlightenment. The two main types used in Buddhism are concentration/focus/mindfulness and insight meditations, with variations in the various sects $[3,8,9]$ both have comprehensive explanations of various meditative practices. According to Buddha, in The Dhammapada 282. Through meditation, wisdom is won, through lack of meditation, wisdom is lost; let a man who knows this double path of gain and loss so conduct himself that wisdom may grow [10].

\section{The Concept of Suffering}

Like so many words I am finding in my readings that are difficult to translate in English in a way that truly explains their concepts, the term dukkha is difficult to translate in order to convey its true meaning. Dukkha lies at the heart of Buddha's teachings and, to me, it is one of the most difficult to grasp or understand by its popular translation of "suffering." His Holiness the Dalai Lama says that, "the first step we must take as practicing Buddhists is to recognize our present state [of being, living] as dukkha or suffering, frustration and unsatisfactoriness" $[5,6]$. Buddhist teachings describe three main "levels or types of suffering. The first is called 'the suffering of suffering', the second, 'the suffering of change', and the third is 'the suffering of conditioning'" [5,6]. The first type consists of those painful experiences related to being physically human birth, sickness, aging, and death. The second type is happy or pleasurable. These experiences occur in our present unenlightened state and are therefore transient. We suffer when we perceive them, when the intensity of the experience ebbs, as temporal and short-term yet we desire to have them be permanent. I have found an explanation that helps to understand the paradox of happiness as suffering. The suffering of change is perceived as suffering because happiness and joy are on the opposite end of a continuum where pain and painful experiences represent the opposing end. From a dualistic perspective, they are the relief, or opposite of pain. And because change is a part of life, joy inevitably and eventually changes to something else, resulting in the experience of dukkha.

The third type of suffering is the existential realization that suffering will always be present as long as we continue to live in an unenlightened existence. There will always be something that causes suffering. This realization can lead to an existential crisis. And, according to the Dalai Lama, it is called the suffering of condition "because this state serves as the basis not only for painful experiences in this life, but also for the causes and conditions of suffering in the future" [6]. As Gunaratne metaphorically sums it up, "The axe of impermanence is always there to fell the tree of joy" [2]. Perhaps happiness, one end of the continuum, with unhappiness or dukkha at the other end, causes suffering if one attaches to keeping the feeling. Personally, though, I could recognize the feeling of happiness as an illusion and attachment and either choose to remain detached from the feeling or experience the physicalmental-spiritual sense in the moment and let it go neutrally until the next moment. I wonder how Buddhists who live happily really experience it. To [2], the closest approximation of dukkha in English is "disharmony". He sees it as "inherent in the very formation of the human being". It "is an experience of the internal world of the self". He further expounds on the concept by breaking down the word. The word 'Dukkha' is made up of two words 'Du' and 'Kha', 'Du' is a prefix meaning bad, low, mean, base or vulgar. 'Kha' means empty or hollow. The two words taken together therefore refer to that which is bad because it is empty, unsubstantial, unsatisfactory or illusory. It refers to a state of unsatisfactoriness if one may use the expression. The popular rendering of Dukkha as 'suffering' is not quite satisfactory since the word 'suffering' is likely to convey the idea of pain only and does not introduce the idea of unsubstantiality or illusorines. Dukkha consists of a state of unbalance, that continued agitation and disturbance to which all beiigs sic, beings are subject by reason of the absence of stability and permanence in this world by reason of the never ending rise and fall of things leading to a universal 'unsatisfactoriness' or disharmony [2].

So, it seems that human beings, by the act of reincarnation and being born, are contractually bound to dukkha by the initiatory experience of birth. One can feel despair at just being born. Dukkha is inherent in living in this third-dimensional existence. It is like the metaphor of "hitting the ground running" (birth) and not stopping until one has reached the end of the road (physical death). It is as if an animal sense of survival is necessary, which is dukkha. It is a package deal the vehicle of the physical body and existence come standard with dukkha. However, esoterically, if we choose to be reincarnated in order to hasten our spiritual development, then wouldn't' coming into an existence of disharmony provide the impetus and drive to spiritually develop and stop reincarnating? I find this viewpoint both helpful and hopeful. Translator Moore JH [11] explains suffering as craving. Any craving creates an attachment to something. The something exists in our world, which is transient and illusory. Therefore, whatever we crave will not last. Put another way, this world is an illusion (samsara in Sanskrit), so whatever object we crave is also an illusion. The loss of the object creates feelings of grief and loss, which generates more attachment by the intensity of these feelings. It becomes an endless cycle. Naradamaha Thera's translation of dukkha is that of "painful feeling", "basis of pain", "object of pain", "cause of pain", or "conditioning state of pain" [12]. Buddha is said to have identified eight causes of dukkha: birth, death, decay, disease, "association with the unpleasant", "separation form the beloved", when one does not obtain what one desires", and the Five Aggregates matter, sensations, perceptions, mental formations, and consciousness [12].

The Bhikkhu Silacara translates Buddha's first sense of dukkha, when he was sitting under the Bodhi tree as thus: "Idan pi Dukkka Here verily is Ill [13]. The Bhikkhu Silacara dispels the assertion that Buddhism, because of the concept of dukkha, is pessimistic. Pessimism is an attitude of mind toward a fact, and what the Buddha does in the first Four Noble Truths is only to call attention to a fact, not a word being said to prevent one from adopting whatever attitude he chooses toward the fact [13]. It is the subsequent revelation that there is hoped to be found in Buddha's knowledge of a solution that is enough to dispel such a contention. In the Dhammapada, Buddha states: 
A. 277. All existing things are transient.' He who knows and sees this cease to be [in] the thrall of grief.

B. 278. All existing things are involved in suffering.' He who know and perceives this cease to be [in] the thrall of grief.

C. 279. All existing things are unreal.' He who knows and perceives this is no longer [in] the thrall of grief [10].

So far, we have discussed dukkha from the perspective of its meaning and its place in human existence which, according to Buddhist teachings, is the First Nobel Truth. According to Gunaratne VF [2], once one understands the First Noble Truth, that all life is dukkha, the Second Noble Truth naturally arises. And once the Second Noble Truth is understood, the cause of dukkha, the Third Noble Truth naturally presents itself, that there is a way to rid ourselves of dukkha, and so on. The Four Noble Truths are logically progressive. All four-address dukkha but answer a different question. The First Noble Truth makes the statement that life is dukkha. The Second Noble Truth therefore addresses the cause of dukkha, which is craving (Tanha in Pali; Trushna in Sanskrit), or selfish craving $[2,11,13]$. The Dalai Lama explains it as "those emotional experiences that lead to confusion, and which affect the mind [5].

The Third Noble Truth is that there is a way to end dukkha, to free us of its cycle and experience. Dukkha is eliminated by ridding ourselves of the cause, craving and desire, by renouncing it and our ignorance of its presence and cause [2]. As the Bhikkhu Silacara puts it: To cease from Craving, then, while it involves the removal of the motives that usually impel men to activity by no means imports the cessation of all activity. There is a greater call than ever for the display of energy, but it is energy directed in an altogether new channel [13]. Liberation from dukkha, according to the Dalai Lama, has four characteristics: "cessation of the continuum of afflictions", "true peace", "ultimate satisfaction", and "definite emergence from the process of unenlightened existence" [6].

The Fourth Noble Truth explains Buddha's method of achieving cessation of dukkha, which is called the Noble Eightfold Path, and uses the vehicle of meditation to achieve cessation and attain enlightenment. In Buddha's words, in the Iti Vuttaka, a summary of the Four Noble Truths is thus:

i. The self-composed, mindful

ii. And thoughtful disciple of Buddha,

iii. Comprehendeth the Cravings,

iv. And the Cause of the Cravings,

v. And Comprehendeth where they cease,

vi. And the Path that leadeth to their destruction.

vii. By the destruction of (his) Cravings,

viii. This monk hath extinguished Hunger, and hath attained Nirvana [11].
And in the Dhammapada, Buddha says:

A. 190. He who takes refuge with Buddha, the Law and the Order; he who with clear understanding sees the four noble truths.

B. 191. Suffering, the origin of suffering, the destruction of suffering, and the eightfold noble path that leads to the release from suffering.

C. 192. That is the safe refuge, that is the best refuge; having gone to that refuge, a man is delivered from all suffering [10].

\section{Personal Understanding of Dukkha}

The importance of understanding the nature of dukkha, or suffering, cannot be overemphasized. According to His Holiness the Dalai Lama, "it is so crucial to realize the nature of suffering, because the stronger and deeper your insight into suffering is, the stronger your aspiration to gain freedom from it becomes" [6]. The premise is that insight leads to understanding, which leads to release. The term "suffering" has a very negative connotation to me. And the concept that all life is suffering rubs me the wrong way. I bristle at the notion. After the extensive reading I did for this paper, I feel less antagonism and I have a much better understanding of dukkha. I do not believe that term "suffering" is an appropriate translation of dukkha I think it is misleading. I propose the following definition instead: Dukkha is the state of being that begins at birth, lasts through life, ends in death, and returns in rebirth. It is a state of being involving internally generated attachments, emotions, and thoughts which, in our unenlightened state, we perceive as permanent when in fact they are not. Our desire for attachment, our cravings for transient situations and objects, results in our experience of dissatisfaction, grief, despair, and disharmony with life. This is dukkha.

\section{Acknowledgement}

None.

\section{Conflict of Interest}

No conflict of interest.

\section{References}

1. Conze E (1980) A short history of Buddhism. George Allen \& Unwin, London, Australia.

2. Gunaratne VF (1968) The significance of the four noble truths. Buddhist Publication Society, Ceylon, Sri Lanka.

3. Harvey P (1990) An introduction to Buddhism: Teachings, history, and practices. Cambridge UK: Cambridge University Press.

4. Robinson R, Johnson W (1977) The Buddhist religion: A historical introduction ( $2^{\text {nd }}$ edn). Belmont Wadsworth Publishing, CA, USA.

5. Dalai Lama T (2000) A simple path: Basic Buddhist teachings by his holiness the Dalai Lama (GT Jinpa Trans). Thorsons, London, Australia.

6. Dalai Lama T (1997) The four noble truths: Fundamentals of the Buddhist teachings. His holiness the XIV Dalai Lama (GT Jinpa Trans). Thorsons, London, Australia.

7. Rahula W (1959) What the Buddha taught (revised edn). Grove Press, New York, USA. 
8. Goleman D (1972a) The Buddha on meditation and states of consciousness, part 1: The teachings. The Journal of Transpersonal Psychology 4(1): 1-44.

9. Goleman D (1972b) The Buddha on meditation and states of consciousness, part II: A typology of meditation techniques. The Journal of Transpersonal Psychology 4(2): 151-210.

10. Babbitt I (1936) The Dhammapada: Translated from the Pali with an essay on Buddha and the Occident (I Babbitt, Trans). New Directions Books, New York, USA.
11. Moore JH (1908) Sayings of Buddha: The Iti-Vittaka. Columbia University Press, New York, USA.

12. Thera NM (1956) A manual of Abhidhamma: Abhidhammatha-Sangaha: Edited in the original Pali text with English translations and explanatory notes. BBD Power Press, Bangalore, India.

13. Silacara TB (1922) The four noble truths (2 ${ }^{\text {nd }}$ edn). Theosophical Publishing House, Madras, India. 